\title{
Deviations in behavior and productivity data before diagnosis of health disorders in cows milked with an automated system
}

\author{
M. T. M. King, ${ }^{*}$ K. M. Dancy, ${ }^{*}$ S. J. LeBlanc,† E. A. Pajor,ł and T. J. DeVries*1 \\ *Department of Animal Biosciences, and \\ †Department of Population Medicine, University of Guelph, Guelph, Ontario, N1G 2W1, Canada \\ †Faculty of Veterinary Medicine, University of Calgary, Calgary, Alberta, T2N 1N4, Canada
}

\begin{abstract}
To explore potential changes in behavior and productivity useful for early detection of health disorders in cows milked with automated milking systems (AMS), we collected longitudinal data throughout lactation of 57 dairy cows housed in a freestall barn with an AMS. Health problems were recorded, including subclinical ketosis (SCK; $\mathrm{n}=19)$, metritis $(\mathrm{n}=11)$, hoof disorders $(\mathrm{n}=14)$, pneumonia $(\mathrm{n}=7)$, and displaced abomasum ( $\mathrm{DA} ; \mathrm{n}=5)$. Data on rumination, activity, milking frequency and yield, and lying behavior were recorded electronically. Using repeated-measures mixed linear regression models, these data were analyzed for the days before the day of diagnosis/treatment ( $d \quad 0)$ for each disorder separately, controlling for days in milk and parity. Analyses were performed between the day on which each outcome variable deviated significantly from baseline (up to $\mathrm{d}-14$ ) and the day before diagnosis (nadir at $\mathrm{d}-1$, before treatment and recovery). Outcomes tested were 3-d rolling averages of milk yield, milking frequency, and AMS supplement intake, in addition to daily rumination time (DRT), body weight, milk temperature, activity (measure of head/neck motion), and 3 lying behavior variables. From d $-8,-6$, and -5 before diagnosis of DA, SCK, or pneumonia, respectively, DRT declined by 45,25 , and $50 \mathrm{~min} / \mathrm{d}$. From d -14 to -1 before diagnosis of hoof disorders, DRT declined by $3 \mathrm{~min} / \mathrm{d}$. Body weight declined from $\mathrm{d}-4$ before pneumonia $(-14 \mathrm{~kg} / \mathrm{d})$ and metritis $(-13$ $\mathrm{kg} / \mathrm{d})$, from d -6 before SCK $(-10 \mathrm{~kg} / \mathrm{d})$, and from d -5 before hoof disorders $(-5 \mathrm{~kg} / \mathrm{d})$. Milk yield declined by 4.4 and $4.1 \mathrm{~kg} / \mathrm{d}$ from d -4 before DA and pneumonia diagnoses, respectively, and by $1.2 \mathrm{~kg} / \mathrm{d}$ from d -5 before SCK diagnosis. Activity levels declined before diagnosis of DA, pneumonia, SCK, or metritis. Lying behavior changed before diagnosis of DA, pneumonia, or metritis. Our results provide evidence that rumination behavior often deviated before milk yield
\end{abstract}

Received February 13, 2017.

Accepted June 3, 2017.

${ }^{1}$ Corresponding author: tdevries@uoguelph.ca and that several variables could contribute to earlier or automated identification of disorders. Behavior and productivity changed differently in association with various health disorders, suggesting the potential to distinguish among health problems. These variables merit further investigation in larger studies of cows milked with AMS.

Key words: robotic milking, behavior, productivity, health disorder, detection

\section{INTRODUCTION}

Automated milking and behavior monitoring systems are gaining popularity worldwide. To improve the welfare and productivity of both dairy cows and producers, these technologies must be thoroughly tested and validated before being relied upon. Automated milking systems (AMS) record a vast amount of data and are often coupled with electronic monitors of behavior, including rumination and general cow activity. Many alerts and reports (i.e., attention lists) are generated using these data, either helping producers or, in other cases, overwhelming them with partially reliable or actionable information. Health alerts often flag cows showing deviations in their milk yield, rumination time, and other variables, but it is imperative that these reports be precise, efficient, and validated. Although many AMS attention lists are supported by research, others remain untested or are undisclosed under patents or commercial property. Therefore, users must combine field experience with science-based recommendations to generate illness attention reports and to select settings for each farm.

The negative implications of lameness for cow welfare and productivity in AMS have been well documented (e.g., Bach et al., 2007; Deming et al., 2013; King et al., 2016), but fewer data are available to describe changes in behavior and productivity that precede other health disorders in AMS. Furthermore, little work has evaluated the use of behavior and productivity monitoring for early detection of health issues in AMS specifically. Research in conventional milking systems has identified associations of biological and behavioral changes lead- 
ing up to, and in response to, mastitis (Fogsgaard et al., 2012), milk fever (Liboreiro et al., 2015), metritis (Huzzey et al., 2007; Gáspárdy et al., 2014; Liboreiro et al., 2015; Schirmann et al., 2016), retained placenta (Liboreiro et al., 2015), subclinical ketosis (Goldhawk et al., 2009; Gáspárdy et al., 2014; Liboreiro et al., 2015; Kaufman et al., 2016a,b; Schirmann et al., 2016), clinical ketosis (Gröhn et al., 1999; Itle et al., 2015), and lameness (Bicalho et al., 2008). Additionally, lameness detection models for conventional systems have included milk yield, as well as daily patterns of rumination behavior and a commercial measure of activity in the days leading up to diagnosis (Van Hertem et al., 2013). Patterns of data for cow activity and a commercial index of milking performance were also used to predict lameness in AMS (Garcia et al., 2014). Most recently, Stangaferro et al. (2016a,b,c) evaluated an alert system using a health index score that comprised rumination and activity in a conventional milking system. Those authors assessed alerts for various types of illness and reported that the models for displaced abomasum, ketosis, and indigestion had the greatest specificity, sensitivity, and accuracy, whereas performance of alerts for mastitis and metritis depended on the cause and severity of cases. No study has yet described the changes in these measures preceding different types of health disorders in AMS, nor has any study evaluated the use of lying behavior to detect lameness or hoof disorders in AMS.

Therefore, the objective of this explorative, pilot study was to examine potential changes in productivity and behavior associated with, and preceding, various types of naturally occurring health disorders in a herd of cows milked with an automated system. Outcome variables tested were daily milking frequency, milk yield, AMS supplement intake, BW, daily rumination time (DRT), activity (a unitless measure of head/neck motion), and lying behavior (lying time, bout frequency, and bout duration). We hypothesized that these variables would begin to deviate 1 to $3 \mathrm{~d}$ before diagnosis and that the response could vary based on the type of disorder; in contrast, the null hypothesis was that such variables would not deviate before diagnosis and, therefore, not aid in detection.

\section{MATERIALS AND METHODS}

\section{Animals, Facilities, and Management}

At the University of Guelph, Kemptville Campus Dairy Education and Innovation Center (Kemptville, ON, Canada), we monitored 57 Holstein dairy cows (19 primiparous, 15 in their second lactation, and 23 in their third to sixth lactation). Cows were managed according to the standard operating procedures for this facility, which included limiting the number of cows in the facility to no more than the number of lying stalls. The use of cows and experimental procedures complied with the guidelines of the Canadian Council on Animal Care (CCAC, 2009) and were approved by the University of Guelph Animal Care Committee (AUP\#2709). All cows in the research herd (maximum 52 lactating cows at any one time) were sampled to provide data for all lactating animals present at the facility. Exclusion criteria were that cows must not be enrolled in any other trial and, therefore, were managed only according to protocols for the milking herd. If a cow was enrolled in another research trial, any data past that point were removed.

At least 1 wk before their expected calving date, cows were housed in straw-bedded box stalls (3 isolation stalls approximately $15 \mathrm{~m}^{2}$ each) with outdoor access and enrolled in the study. Within $24 \mathrm{~h}$ after calving, cows were moved to the main herd, provided that no severe health complications had developed during that time. The milking herd was housed in a freestall facility with free cow traffic to a single AMS unit (Lely Astronaut A3 Next, Lely Industries N.V., Maassluis, the Netherlands). Barn staff fetched cows 2 times per day to ensure that cows did not go without milking for $>10$ to $12 \mathrm{~h}$ since their last AMS visit. The facility had 52 freestalls with water mattress bases (DCC Waterbeds, Advanced Comfort Technology Inc., Reedsburg, WI), arranged in 2 head-to-head rows. Lying stalls had a mean bed length of $2.74 \mathrm{~m}$ and measured $1.16 \mathrm{~m}$ wide, center to center, with the neck rail positioned $1.27 \mathrm{~m}$ above the stall bedding surface and $1.81 \mathrm{~m}$ from the rear curb. The mean distance from the brisket board to the back of the stall was $1.94 \mathrm{~m}$ and the curb height was $0.20 \mathrm{~m}$. Freestalls were bedded with wooden shavings once per week and raked twice daily. Cows had access to 2 water troughs $(180 \times 35 \mathrm{~cm})$, one at each end of the pen. All flooring was made of scarified concrete, including the alley near lying stalls, the feed alley, and crossover alleys. Alley floors were cleaned using a cabledriven automated scraping system (GEA Houle Inc., Drummondville, QC, Canada), which removed manure 12 times per day.

Cows were fed a partial mixed ration containing, on a DM basis, $15 \%$ high-moisture corn, $31 \%$ corn silage, $41 \%$ haylage, and $13 \%$ protein concentrate. Feed was mixed once per day in a TMR mixer wagon (Jaylor 4425, Jaylor Fabricating, East Garafraxa, ON, Canada) and delivered once per day at approximately $1030 \mathrm{~h}$. At least one headlock with feedbunk access was available for each cow at any time (a total of 55 headlocks spaced at $0.74 \mathrm{~m}$ center to center). Supplemental concentrate pellets fed in the AMS (supplied by Dundas 
Feed \& Seed Ltd., Winchester, ON, Canada) included the ingredients wheat shorts, soybean meal, corn, corn distillers grains, oat by-product, molasses, dry fat, calcium carbonate, dicalcium phosphate, choline chloride, salt, vitamins, trace minerals, pellet binder, and flavor/ attractant. The amount of supplement offered was determined automatically by the AMS computer using feed tables accounting for parity, stage of lactation, and milk yield. Beginning in January 2015, a fresh cow pellet (supplied by Grand Valley Fortifiers, Cambridge, ON, Canada) was fed to cows $<30$ DIM, which included the ingredients wheat shorts, soy hulls, soybean meal, corn distillers, glycerol, beet pulp, vitamins, and minerals. From 0 to 50 DIM, cows were given permission to milk no more than $5 \times / \mathrm{d}$ or when their expected milk yield exceeded $5.5 \mathrm{~kg}$ per milking, whichever occurred first. From 50 DIM onward, cows could be milked at that same frequency (no more than $5 \times /$ d) or with an expected milk yield of $6.0 \mathrm{~kg}$ per milking, whichever occurred first.

\section{Data Collection}

Data were collected from September 1, 2014, to September 28, 2015. The average environmental temperature during this period was $6.9 \pm 12.8^{\circ} \mathrm{C}$; data were retrieved from the Environment Canada weather station in Kemptville, Ontario, Canada. All cases of health problems and treatments were recorded by barn staff (3 individuals in total) according to standard operating procedures of the research station; these diagnoses were conducted by barn staff and, when necessary, by 1 of 2 herd veterinarians. Displaced abomasum (DA) was diagnosed when cows were off feed with a gas-filled abomasum on the left or right side, diagnosed by a "ping" sound on percussion by a veterinarian, followed by surgery. Pneumonia was defined as a fever (rectal temperature $\geq 39.5^{\circ} \mathrm{C}$ ), heavy breathing, increased respiratory rate, and nasal discharge. Whole-blood BHB concentrations were measured electronically with a handheld meter (Precision Xtra, Abbott Diabetes Care, Inc., Alameda, CA; validated by Iwersen et al., 2009) to detect cases of subclinical ketosis (SCK; BHB $\geq 1.2$ $\mathrm{mmol} / \mathrm{L}$, as recommended by Duffield et al., 1997). The barn staff tested cows twice postpartum at $13.5 \pm 8.9$ DIM; the first BHB test was conducted between 4 and $18 \mathrm{DIM}$ and the second approximately $7 \mathrm{~d}$ later. Cases of hoof disorders were diagnosed when mechanical or infectious lesions were detected by barn staff or during routine semi-annual hoof trimming, and treated with corrective hoof trims. Types of hoof disorders included digital dermatitis, interdigital dermatitis, sole ulcers, and abscesses. Finally, cases of metritis were identified by foul-smelling vulvar discharge and a rectal tempera- ture $\geq 39.5^{\circ} \mathrm{C}$ in cows $<20$ DIM; these diagnoses were made by barn staff and a veterinarian when necessary.

Visits to the AMS and other related information were recorded automatically by the AMS. This included visit success, milk yield, milk temperature, amount of concentrate supplement fed, and BW. Daily milk yield was calculated as the sum of all milk collected per cow per day, whether it was from a successful or failed milking. Successful and failed milkings, respectively, were defined as those at which teat cup attachment was successful or not, and whether the amount of milk collected either exceeded or did not meet the system requirement to qualify as a milking event (i.e., at least $80 \%$ of a cow's expected yield for that milking). Only data from complete days (0000 to $2359 \mathrm{~h}$ ) were used in the analyses. Daily milk yield, frequency, and supplement intake data were later converted to 3 -d rolling averages to reduce day-to-day variation (due to variable timing of milkings per day), similar to Gomez et al. (2015), in which a 5-d rolling average was used.

Rumination time and activity data were collected by electronic rumination detection loggers on the neck collar of each cow in 2-h intervals (Lely Qwes-HR collars, Lely Industries N.V.). The collection of rumination data using these collars has been validated by Schirmann et al. (2009). Cow activity was recorded as a unitless measure of upward vertical head and neck movements, such as walking and mounting, while excluding downward vertical and horizontal movements such as feeding (Elischer et al., 2013). The accuracy of these collars' activity data has been validated to an extent in a pasture-based AMS; the collars recorded walking behavior with a moderate degree of accuracy but did not reliably differentiate between standing and lying behavior (Elischer et al., 2013). These data were transferred at each milking via an automatic reader located in the AMS, and were then summarized by day and separated into sums of day and night values; night was defined as 1801 to $0800 \mathrm{~h}$ and day as 0801 to 1800 $\mathrm{h}$. These sums were then converted into ratios of night: day activity and rumination.

Lying and standing behaviors were recorded continuously using electronic HOBO data loggers (Onset Computer Corp., Bourne, MA), taking measurements of leg orientation at 1-min intervals (validated by Ledgerwood et al., 2010). Data loggers were wrapped in and attached, using veterinary bandaging tape (Vetrap, 3M Products, St. Paul, MN), to the medial side of the lower hind leg. The first fitting with a data logger occurred at least $6 \mathrm{~d}$ before the expected calving date. Following enrollment, loggers were switched $1 \times /$ wk to provide cows with a fresh wrap and to download collected data. Before a logger was removed, a new logger was fitted to the other hind leg of the cow. These data were used to 
calculate daily lying time, frequency of lying bouts, and mean daily lying bout duration ( $\mathrm{min} /$ bout).

\section{Statistical Analyses}

After data collection was complete, an estimated minimum sample size for each disorder was retrospectively determined through power analysis using WinPepi version 11.62 (Abramson, 2011). Estimates of standard deviation and differences in rumination behavior, activity, and milk yield from previous studies were used (Van Hertem et al., 2013; Liboreiro et al., 2015; Kaufman et al., 2016a). Data for all cows were grouped and analyzed by health disorder; only those with a sufficient number of cases over the course of the study were used in statistical analyses to minimize variation due to the small sample size. Additionally, because cases of metritis, pneumonia, and SCK were diagnosed soon after calving in this study, we present only the preceding 4 to $8 \mathrm{~d}$ of data because of a lack of precalving data for measures requiring proximity to the AMS for upload (all measures except lying behavior). For DA and hoof disorders, we present the preceding 12 and $14 \mathrm{~d}$, respectively.

The timing of diagnoses (median, range) were as follows: metritis (5, 3-16 DIM; $\mathrm{n}=11)$, SCK $(10,5-24$ DIM; $\mathrm{n}=19)$, DA $(19,12-34$ DIM; $\mathrm{n}=5)$, clinical pneumonia $(4,2-76$ DIM; $\mathrm{n}=7$ ), and hoof disorders $(105,4-302$ DIM; $\mathrm{n}=14)$. Although 57 cows were monitored, the total incidence of all disorders was 56; some cows were afflicted with multiple types of disorders over the course of their lactation. Those cows were included in multiple groups based on the day they were diagnosed with each particular disorder; health problems that occurred with no other issue or another event $>55 \mathrm{~d}$ apart are referred to as independent cases. Of the $5 \mathrm{DA}$ events, 3 cases occurred within 1 to $5 \mathrm{~d}$ of other afflictions, and the remaining 2 cases occurred $>20 \mathrm{~d}$ after previous sickness. Of the 19 cases of SCK, 5 cases occurred independently, 5 cases occurred 1 to $8 \mathrm{~d}$ before any other afflictions, and the remaining 9 cases occurred within 0 to $18 \mathrm{~d}$ after other problems. Of the 7 cows with pneumonia, 5 cases occurred independently and 1 case occurred $6 \mathrm{~d}$ after another health event and the other occurred $4 \mathrm{~d}$ before another event. Two of 14 cows had hoof disorders $5 \mathrm{~d}$ before other health problems, and the remaining 12 cases occurred independently.

Before analyses, all data were screened for normality and outliers using the UNIVARIATE procedure of SAS (v. 9.4, 2013; SAS Institute Inc., Cary, NC). Outcome variables tested were daily means of milk yield (3-d rolling average; $\mathrm{kg} / \mathrm{d}$ ), milking frequency (3-d rolling average; no. of successful milkings/d), rumination time (min/d), AMS supplement intake (3-d rolling average; $\mathrm{kg} / \mathrm{d})$, BW (kg), milk temperature $\left({ }^{\circ} \mathrm{C}\right)$, activity (unitless), and lying behavior (lying time, bout frequency, bout duration). We also examined ratios of night:day rumination and night:day activity by comparing the sum of values from 1801 to $0800 \mathrm{~h}$ relative to the sum from 0801 to $1800 \mathrm{~h}$ ); those hours were chosen to reflect daylight hours and management routines. Variables that were not normally distributed were transformed by using the natural logarithm function (for night: day rumination ratio for all 5 disorders and for lying bout duration for DA), or the exponential function (for night:day activity ratio for metritis and pneumonia).

We then analyzed all data in repeated-measures mixed linear regression models (the MIXED procedure of SAS, v. 9.4), treating DIM (continuous data) and parity (categorized as 1,2 , or $\geq 3$ lactations) as fixed covariates for all models. The random effect in each model was cow. A first-order auto-regressive covariance structure was used for all models based on best fit according to the lowest Bayesian information criterion values, with cow as the subject of the repeated measure. Residuals for each model (i.e., for each variable for each health disorder) were examined for normality and heteroscedasticity to ensure the assumptions of mixed linear regression models were met. The effect of day relative to the day of diagnosis (d 0) was first tested as a continuous predictor variable in univariable analyses for each outcome variable and each health disorder separately. Days-to-diagnosis values ranged from d -14 to -1 to include a period during which stable trends and deviations in data occurred; this was determined based on visual observations of each cow's data separately, as well as mean values for each disorder. Data were analyzed until d -1 , the nadir in most cases, because recovery began soon after diagnosis and treatment on d 0 . Those variables with $P>0.25$ in univariable analyses were not included in any later analyses for that disorder; these associations were also examined by visual inspection of cow-level graphs for each disorder. Other statistical methods available included partial least squares discriminant analysis (as used by Garcia et al., 2014; $\mathrm{n}=88$ ), and multivariate logistic regression models in combination with cross-validation (used by Van Hertem et al., 2013; $\mathrm{n}=118$ ). Those methods were not used in the current study because of the small sample of cows available.

For variables with $P<0.25$, days-to-diagnosis was then examined as a categorical fixed effect and repeated measure for each disorder separately, with parity and DIM as covariates, to determine the point of inflection and deviation using Tukey's test. Tukey's test was used to determine day-by-day differences for each outcome variable and to determine the day at which each vari- 
able deviated significantly $(P \leq 0.05)$ from the baseline or tended to do so $(P \leq 0.1)$. The baseline of each variable was defined as those days between which there were no significant differences or trends among days $(P$ $>0.1$, while allowing for one single outlier day at a time. If an outcome variable deviated from the baseline for more than 1 consecutive day $(P \leq 0.10)$, the slope was analyzed between the point at which the variable began to deviate until the nadir at $d-1$. Slopes of the estimated change in each variable were calculated in similar mixed-effect linear regression models, using days-to-diagnosis as a continuous measure, and DIM and parity as fixed covariates, to determine the degree of change occurring before diagnosis. If no single day of deviation was significant using Tukey's test but the slope between the baseline and a value $2 \mathrm{~d}$ later had $P<0.1$ from baseline, that inflection point was considered the day of deviation. If no significant deviation was present, the slope of the entire period was analyzed; if this slope was $0.10<P<0.25$, this variable was not reported as a significant association and was also confirmed by visual inspection of cow-level graphs.

\section{RESULTS AND DISCUSSION}

This longitudinal pilot study monitored naturally occurring health disorders in a herd of dairy cows milked with an automated system. Means of production and behavior variables for the entire herd are presented in Table 1. The majority of pre-diagnosis deviations observed in electronic behavioral and productivity data from the AMS were changes in DRT, BW, milk yield, and activity. The response and degree to which these outcome variables changed varied by the type of disorder. Additionally, we observed substantial variation at the cow level, wherein the changes in behavior and productivity of individual cows differed in magnitude, timing, and occasionally direction. In general, reductions in rumination time preceded changes in milk yield and activity by at least $1 \mathrm{~d}$. Depending on the disorder, DRT was reduced by up to $50 \mathrm{~min} / \mathrm{d}$, BW decreased by up to $14 \mathrm{~kg} / \mathrm{d}$, milk yield by up to $4.4 \mathrm{~kg} / \mathrm{d}$, and a commercial measure of activity by up to 34 units/d. Although lying behavior was less indicative of some health problems, certain lying parameters (increasing daily lying time and average bout duration) may contribute to identifying metritis, DA, and pneumonia.

Reductions in DRT were observed before diagnosis with DA, pneumonia, SCK, and hoof disorders. Before DA and pneumonia diagnoses, respectively, DRT decreased by $44.8 \mathrm{~min} / \mathrm{d}(95 \% \mathrm{CI}=-68.0,-21.6 ; P<$ 0.001 ) from $\mathrm{d}-8$ to -1 (Figure 1a) and by $49.7 \mathrm{~min} / \mathrm{d}$ $(95 \% \mathrm{CI}=-99.5,+0.18 ; P=0.05)$ from $\mathrm{d}-5$ to -1 (Figure 2a). While accounting for increasing DRT with

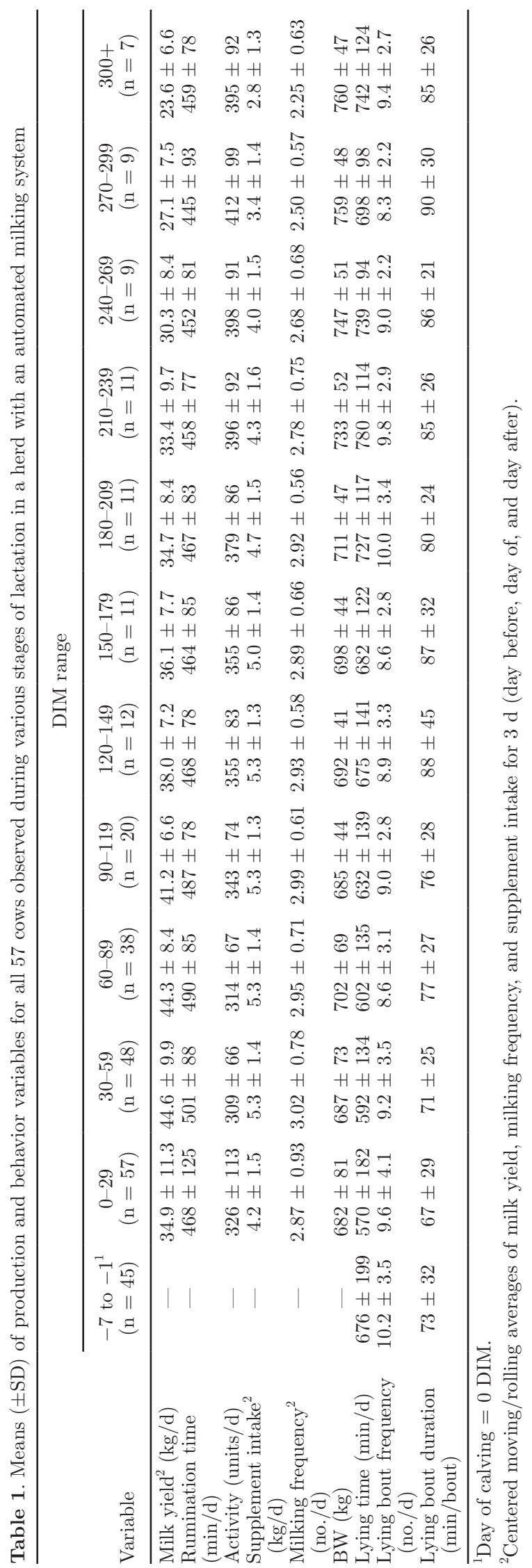


DIM, cows spent $25.5 \mathrm{~min} / \mathrm{d}(95 \% \mathrm{CI}=-42.6,-8.4 ; P$ $=0.004$ ) less time ruminating from $\mathrm{d}-6$ to -1 before SCK detection (Figure 3a). In one study, cows with SCK had reduced postcalving DRT compared with healthy cows, with no difference before calving (Liboreiro et al., 2015). Schirmann et al. (2016) reported the opposite: that SCK cows ruminated less before calving but showed no differences postcalving. Kaufman et al. (2016a) reported increased odds of SCK, as well as SCK with another health disorder, with reduced DRT in the week before and after calving, respectively; however, Schirmann et al. (2016) reported no differences in postcalving DRT between healthy cows and those with SCK. Similarly, Stangaferro et al. $(2016 a, b, c)$ reported lower DRT and more drastic reductions in DRT during the same general timeframe for parlor-milked cows with DA and ketosis compared with healthy individuals; those researchers also observed these trends for mastitis and metritis. We could not analyze cases of mastitis because the majority of those cows were separated and bucket-milked preceding their treatment, which prevented transmission of their rumination and activity data and eliminated the milk and BW data. Additionally, no rumination data were available before calving, which limited our ability to assess associations of DRT with metritis. Although Schirmann et al. (2016) reported no DRT reduction associated with metritis, those with metritis, SCK, and other disorders had lower DMI than healthy individuals. Other researchers have also reported reduced feeding time and feed intake associated with metritis (Urton et al., 2005; Huzzey et al., 2007), subclinical ketosis (Goldhawk et al., 2009), mastitis (Sepúlveda-Varas et al., 2016), and subclinical milk fever (Hansen et al., 2003). A reduction in rumination time before health disorders, as observed in the current study, is therefore consistent with the results of previous research.

From d -14 to -1 before diagnosis of hoof disorders, DRT dropped by $2.9 \mathrm{~min} / \mathrm{d}(95 \% \mathrm{CI}=-5.7,-0.1)$, a substantial total reduction of almost $40 \mathrm{~min}$ total in this time frame $(P=0.04$; Figure $4 \mathrm{a})$; this is comparable to the findings of Van Hertem et al. (2013), who documented reductions of approximately $20 \mathrm{~min}$ in nighttime rumination (2001 to $0400 \mathrm{~h}$ ) within 14 $\mathrm{d}$ of hoof disorder diagnoses. Also during this period, the ratio of night:day rumination time increased $(P=$ 0.001 ), meaning that not only were those cows ruminating less overall each day, but they were also doing so proportionately less during the day (Figure $4 \mathrm{~b}$ ). This result does not necessarily contradict the findings of Van Hertem et al. (2013), who reported that lame cows ruminated less at night; however, they also found inverse, but weaker, correlations of lameness with increased DRT, increased rumination during the day, and reduced night:day rumination time. These differing results could be related to differences in milking system (AMS vs. parlor), management, latitude and sunlight hours, or definitions of night versus day used in each study. The results of the present study support the use of rumination monitoring to assist in early detection of health disorders, and we suggest that this potential component of automated disease detection should be explored in larger studies.

Cows diagnosed with DA, pneumonia, hoof disorders, and SCK exhibited declining milk yields before diagnosis. From $\mathrm{d}-4$ to -1 before diagnosis with DA and pneumonia, milk yield decreased by $4.4 \mathrm{~kg} / \mathrm{d}(95 \%$ CI $=-6.9,-1.9 ; P=0.002 ;$ Figure $1 \mathrm{~b})$ and $4.1 \mathrm{~kg} / \mathrm{d}(95 \%$ $\mathrm{CI}=-6.9,-1.2 ; P=0.01 ;$ Figure $2 \mathrm{~b}$ ), respectively. Accounting for increasing milk yield with DIM $(+1.1$ $\mathrm{kg} / \mathrm{d} ; P=0.004)$, milk yield declined by $1.2 \mathrm{~kg} / \mathrm{d}(95 \%$ $\mathrm{CI}=-2.2,-0.1 ; P=0.03)$ from $\mathrm{d}-5$ to -1 before SCK (Figure 3b). In the $14 \mathrm{~d}$ before hoof disorders, cows produced $0.31 \mathrm{~kg} / \mathrm{d}$ less milk $(95 \% \mathrm{CI}=-0.7$, $+0.1 ; P=0.14)$ from $\mathrm{d}-14$ to -1 ; although not statistically significant, this represents a total reduction of 4 $\mathrm{kg} / \mathrm{d}$ during this 13-d period. Several researchers have reported reductions in milk production before, and following, treatment of lameness (e.g., Van Hertem et al., 2013), although the degree to which this occurs may depend on the type of hoof lesion (Green et al., 2002; Amory et al., 2008; Bicalho et al., 2008). Rajala-Schultz et al. (1999) also reported a reduction in milk yield in cows with ketosis, with milk production declining 2 to 4 wk before diagnosis. Decreased milk production has been associated with metritis and retained placenta in multiparous cows (Dubuc et al., 2011), but daily milk data may not be sufficient to detect metritis so soon after calving. These results support our hypothesis that reductions in milk yield, as measured by an AMS, may serve as an early indicator of certain health issues.

In the current study, BW declined before pneumonia, SCK, hoof disorders, and metritis. Beginning 4 and 6 $\mathrm{d}$ before pneumonia and SCK diagnoses, respectively, cows lost an average of $14.2 \mathrm{~kg} / \mathrm{d}(95 \% \mathrm{CI}=-22.7$, $-5.8 ; P=0.003$; Figure $2 \mathrm{c})$ and $9.6 \mathrm{~kg} / \mathrm{d}(95 \% \mathrm{CI}=$ $-18.1,-1.0 ; P=0.03$; Figure $3 \mathrm{c})$. From $\mathrm{d}-5$ to -1 before corrective hoof trims, BW declined by $4.9 \mathrm{~kg} / \mathrm{d}$ (95\% CI $=-7.3,-2.6 ; P<0.001 ;$ Figure $4 \mathrm{c})$, and from $\mathrm{d}-4$ to -1 before metritis diagnoses, BW declined by $13.5 \mathrm{~kg} / \mathrm{d}(95 \% \mathrm{CI}=-24.4,-2.6 ; P=0.02$; Figure $5 a)$. Reductions in BW may correspond with reduced supplement intake in the AMS, but this was only seen in cows with hoof disorders. From d -14 to -1 relative to diagnosis of hoof disorders (accounting for DIM and parity; Figure 4d), supplement intake tended to decrease by $0.6 \mathrm{~kg}$ total $(-0.05 \mathrm{~kg} / \mathrm{d} ; 95 \% \mathrm{CI}=-0.1$, $0.002 ; P=0.06)$. Supplement intake in the AMS pro- 

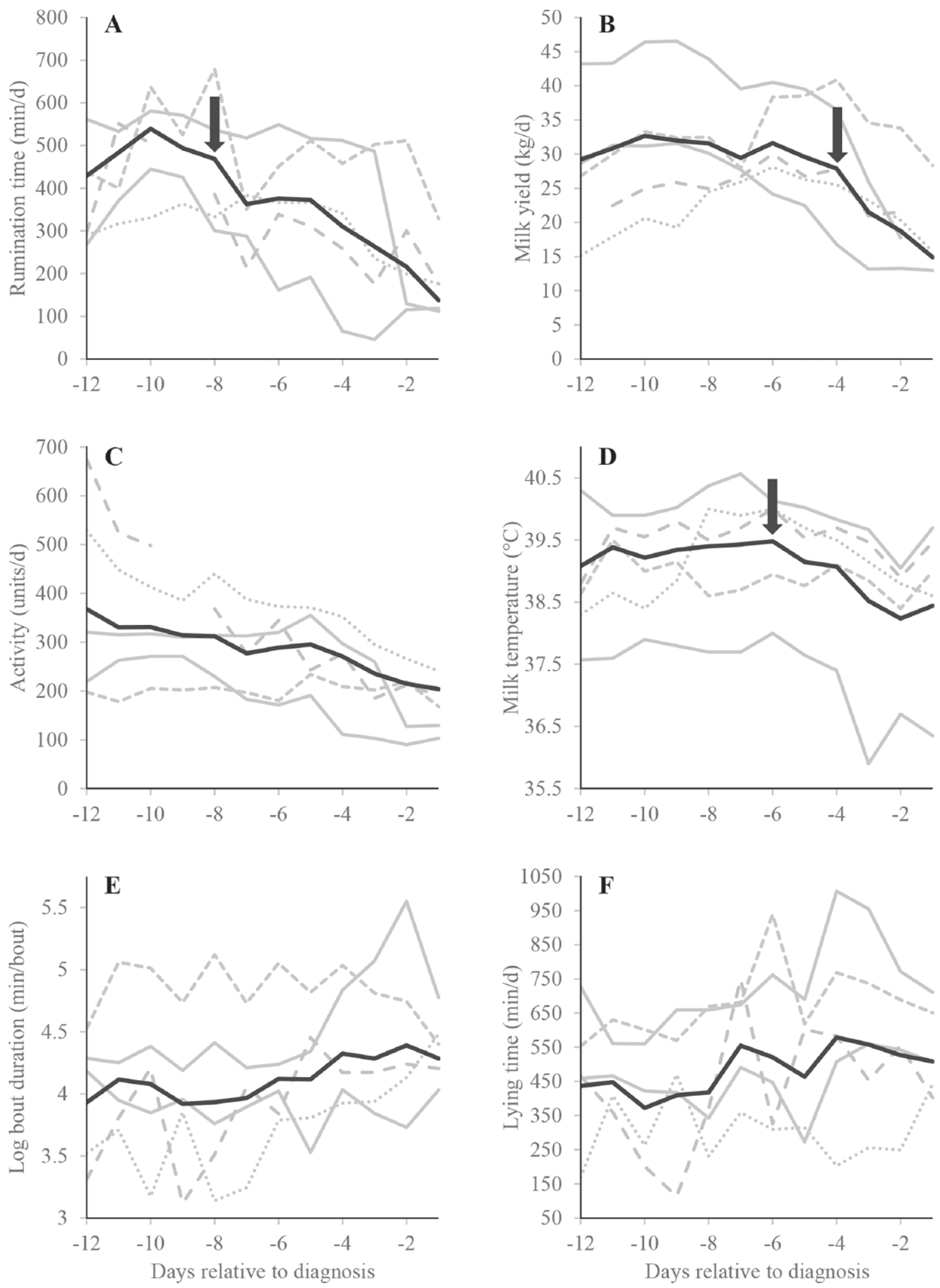

Figure 1. Raw data from d -12 to -1 relative to diagnosis of displaced abomasum $(\mathrm{n}=5)$ for individual cows (gray lines) and least squares means from mixed models controlling for DIM and parity (solid black line) for the following variables: (A) rumination time, (B) milk yield (3-d rolling average), (C) activity, (D) milk temperature, (E) log lying bout duration, and (F) lying time. Downward arrows signify the day on which least squares means deviated $(P \leq 0.10)$ from the previous baseline (no consecutive differences or tendencies among days). 

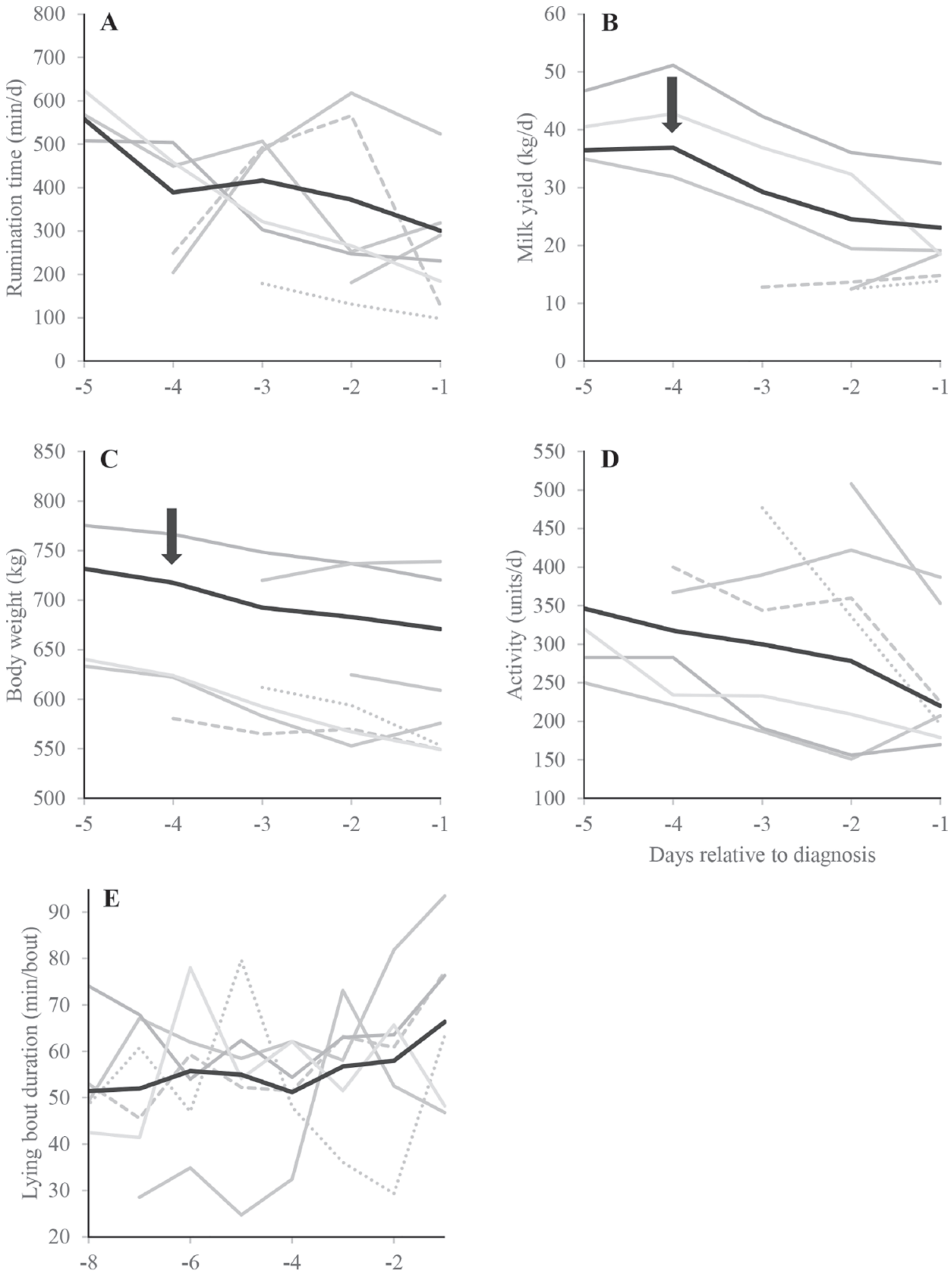

Days relative to diagnosis

Figure 2. Raw data from $\mathrm{d}-5$ to -1 relative to diagnosis with pneumonia $(\mathrm{n}=7)$ for individual cows (gray lines) and least squares means from mixed models controlling for DIM and parity (black solid line) for the following variables: (A) rumination time, (B) milk yield (3-d rolling average), (C) BW, (D) activity, and (E) lying bout duration from $\mathrm{d}-8$ to -1 . Downward arrows signify the day on which LSM deviated ( $P \leq$ 0.10) from the previous baseline (no consecutive differences or tendencies among days). 

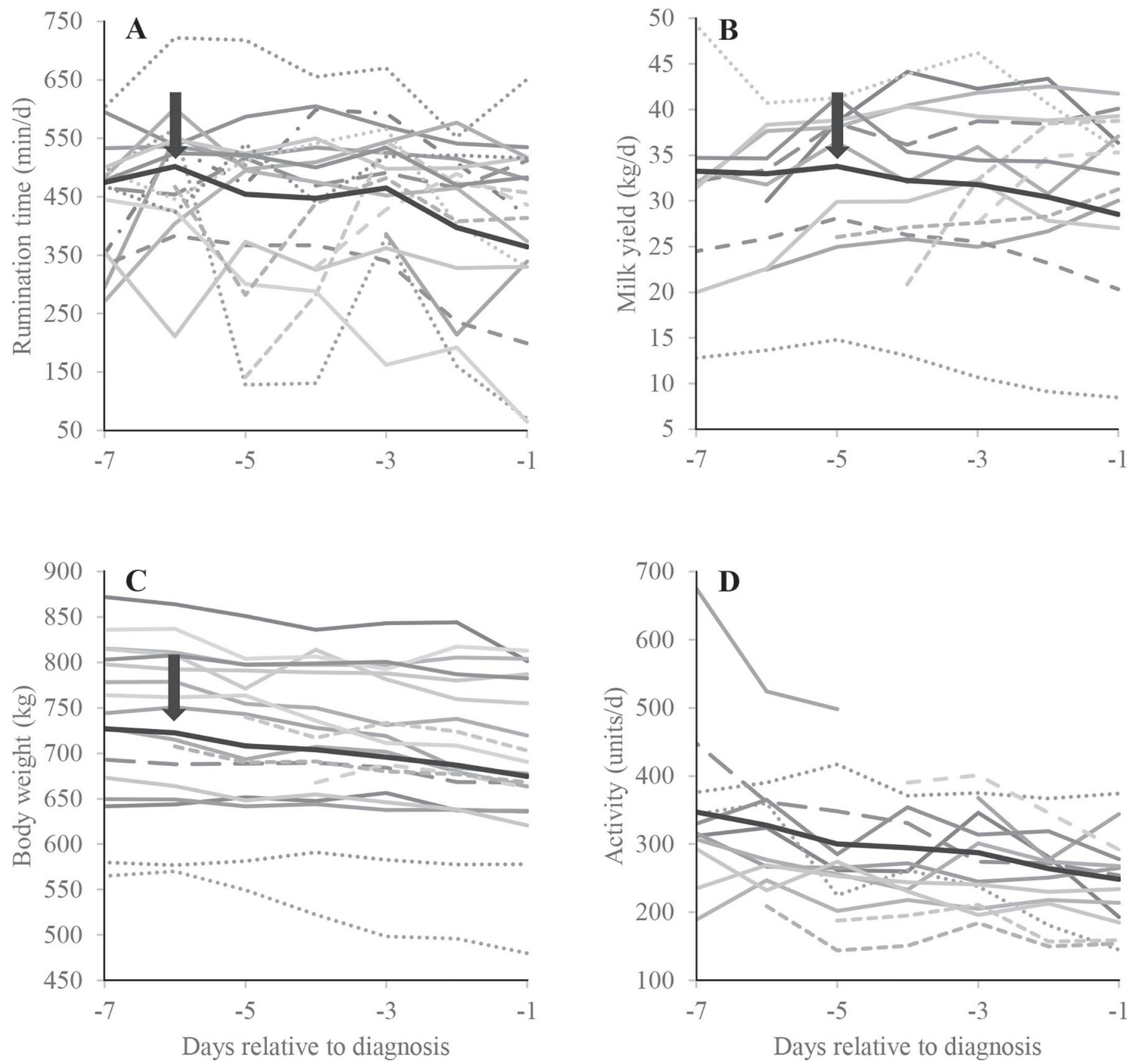

Figure 3. Raw data from $d-7$ to -1 relative to diagnosis of subclinical ketosis $(\mathrm{n}=19)$ for individual cows (gray lines) and least squares means (LSM) from mixed models controlling for DIM and parity (solid black line) for the following variables: (A) rumination time, (B) milk yield, (C) BW, and (D) activity. Downward arrows signify the day on which LSM deviated $(P \leq 0.10)$ from the previous baseline (no consecutive differences or tendencies among days).

vides insight into the amount allotted by the AMS and amount consumed by each cow; it is a unique measure because it is reflective of, and was correlated with, daily milk yield $(\mathrm{r}=0.7 ; P<0.001)$ and milk frequency $(\mathrm{r}$ $=0.58 ; P<0.001)$ for all cows in the study. Although intake of the partial mixed ration at the feed bunk was not measured in the current study, reduced supplement intake and BW may be representative of an overall re- duction in feeding behavior, which is commonly associated with illness in animals (Hart, 1988) and has been documented in cases of metritis (Urton et al., 2005; Huzzey et al., 2007), mastitis (Sepúlveda-Varas et al., 2016), subclinical milk fever (Hansen et al., 2003), and subclinical ketosis (Goldhawk et al., 2009). Additionally, González et al. (2008) reported reductions in feed intake in cows with locomotion disorders before trim- 

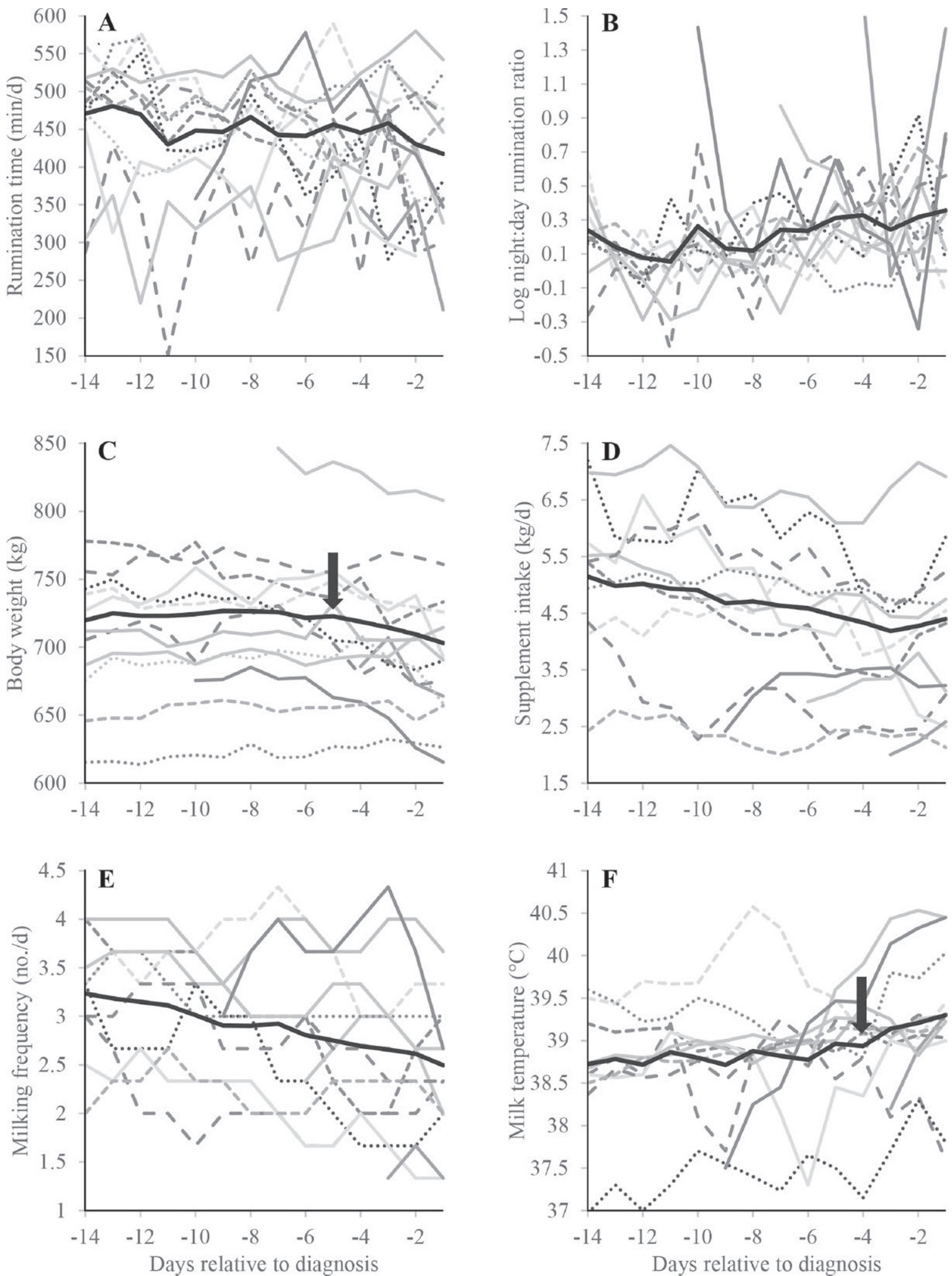

Figure 4. Raw data from $\mathrm{d}-14$ to -1 relative to diagnosis of hoof disorders $(\mathrm{n}=14)$ for individual cows (gray lines) and least squares means (LSM) from mixed models controlling for DIM and parity (solid black line) for the following variables: (A) rumination time, (B) rumination ratio of night:day values (sum of 1801-0800 h relative to sum of 0801-1800 h), (C) BW, (D) supplement intake, (E) milking frequency, and (F) milk temperature. Downward arrows signify the day on which LSM deviated $(P \leq 0.10)$ from the previous baseline (no consecutive differences or tendencies among days). 

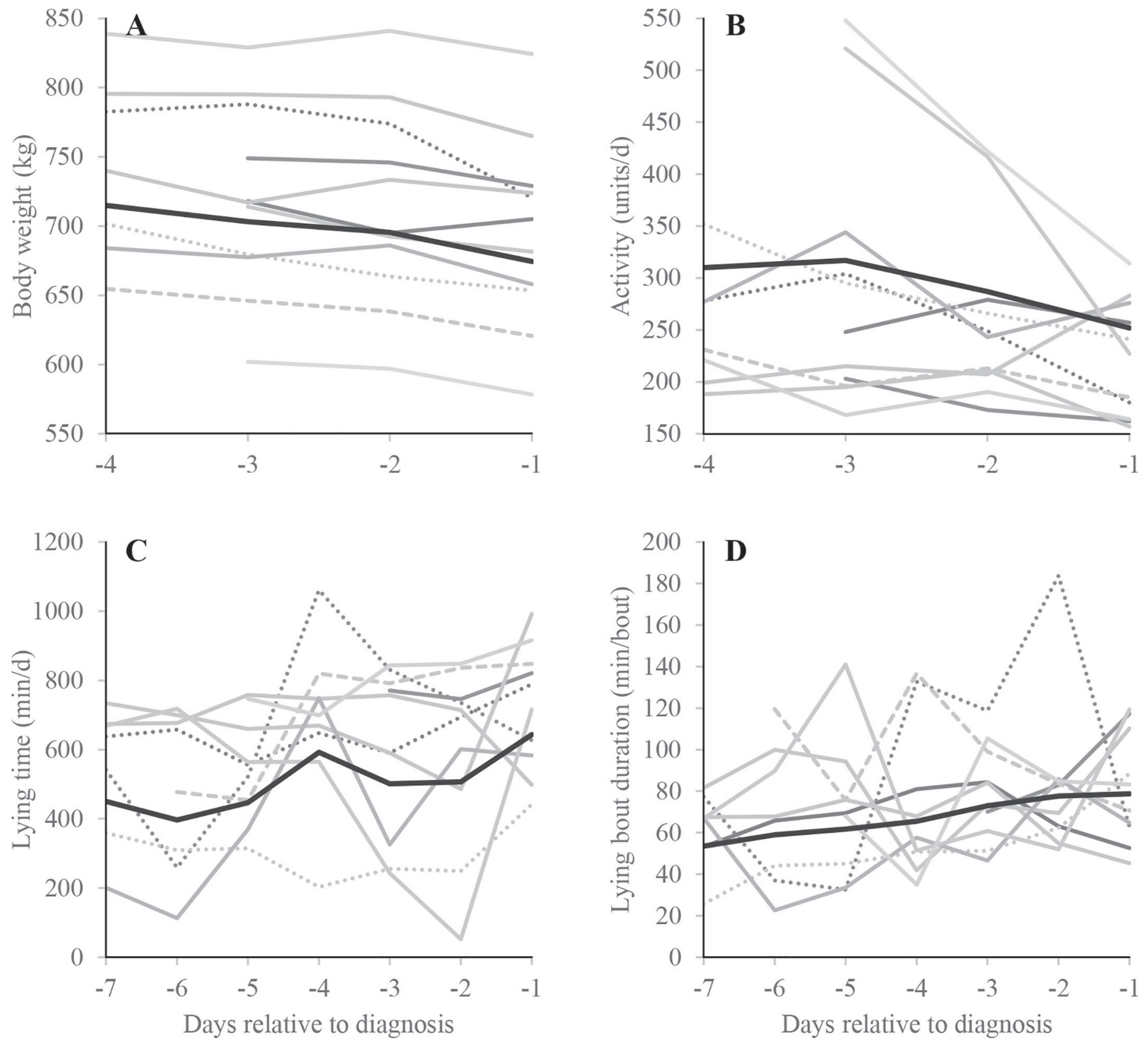

Figure 5. Raw data from $\mathrm{d}-7$ to -1 for lying behavior variables $(\mathrm{n}=10)$ and from $\mathrm{d}-4$ to -1 for other variables $(\mathrm{n}=11)$ relative to diagnosis of metritis for individual cows (gray lines) and least squares means (solid black line) from mixed models controlling for DIM and parity for the following variables: (A) BW, (B) activity,(C) lying time, and (D) lying bout duration.

ming or treatment. It is surprising to note that cows did not exhibit a reduction in BW before DA diagnoses in the current study, because it would be expected that these cows would experience reduced feed intake before diagnoses and a reduction in DRT was observed; this may be a result of the small sample size (5 cows), the variation in timing of BW loss by cow, which was also related to DIM, and the fact that one cow lost no weight before diagnosis.
Activity levels, measured through head and neck motion, declined before diagnoses of DA, pneumonia, SCK, and metritis. Before diagnosis with DA (Figure 1c), activity tended to decrease by $45 \%$ (15 units/d; $95 \%$ $\mathrm{CI}=-31,2 ; P=0.08)$ from $\mathrm{d}-12$ to -1 . From $\mathrm{d}-5$ before pneumonia, activity declined by 34 units/d (95\% $\mathrm{CI}=-58,-10 ; P=0.008$; Figure $2 \mathrm{~d})$, a total reduction of $36 \%$ in activity. From $d-7$ to -1 , the activity of cows diagnosed with SCK declined by 16 units/d (95\% 
$\mathrm{CI}=-27,-6 ; P=0.002 ;$ Figure $3 \mathrm{~d})$, a total reduction of $30 \%$. From d -4 to -1 before metritis diagnosis (Figure 5b), activity tended to decline by $20 \%(-22$ units/d; $95 \% \mathrm{CI}=-46,1 ; P=0.07)$. There was no association between days-to-diagnosis and activity from $\mathrm{d}$ -14 to -1 before hoof disorders, likely a consequence of high variability between cows. Activity levels measured using the same type of monitors as in the current study were also lower and declined more rapidly for cows with ketosis, DA, mastitis, and metritis (Stangaferro et al., 2016a,b,c). Unlike Van Hertem et al. (2013), who observed greater night:day activity ratios for lame cows, we detected no association between night:day activity ratios and days preceding diagnosis of any disorder.

Milking frequency declined only before diagnosis of hoof disorders (Figure 4e). In the $14 \mathrm{~d}$ leading up to diagnosis, daily milking frequency declined by 0.05 milkings/d (95\% CI $=-0.08,-0.02 ; P=0.002)$, a total reduction of approximately 0.6 daily milkings during this period. Despite this reduction in milking frequency being statistically significant, a reduction as small as reported here is unlikely to be useful as an indicator of hoof disorders in a practical setting as it may be too difficult to detect. However, general lameness has previously been shown to reduce milking frequency and voluntary milking behavior (Bach et al., 2007; Deming et al., 2013; King et al., 2017). Milk temperature, on the other hand, increased by $0.17^{\circ} \mathrm{C} / \mathrm{d}$ $(95 \% \mathrm{CI}=0.02,0.32 ; P=0.02 ;$ Figure $4 \mathrm{f})$ from $4 \mathrm{~d}$ before diagnosis of hoof disorders and showed a similar increase from $4 \mathrm{~d}$ before metritis diagnoses $\left(0.23^{\circ} \mathrm{C} / \mathrm{d}\right.$; $95 \% \mathrm{CI}=-0.06,0.5 ; P=0.11)$, although this was not statistically significant. Conversely, milk temperature began to decline from $\mathrm{d}-6$ before $\mathrm{DA}$, by $0.23^{\circ} \mathrm{C} / \mathrm{d}$ $(95 \%$ CI $=-0.38,-0.08 ; P=0.004 ;$ Figure 1d). Field observations indicate that AMS producers monitor milk temperature as a proxy for fresh cow body temperature to indicate disease, particularly metritis. Although the current results suggest that this variable may be useful, it should not be a substitute for visual monitoring of health and actual body temperature, and these values may not fluctuate to a noticeable degree for all cows.

Lying behavior appeared to be less predictive of health issues compared with other measures in the current study. An increase in daily lying time was detected before diagnosis of DA and metritis. The duration of lying bouts increased before DA, pneumonia and metritis, whereas the daily frequency of lying bouts was not associated with days-to-diagnosis of any health disorder. Lying bout duration tended to increase by 1.7 $\mathrm{min} /$ bout per day from $\mathrm{d}-8$ to -1 of pneumonia $(95 \%$ $\mathrm{CI}=-0.2,3.7 ; P=0.08$; Figure $2 \mathrm{e}$ ), resulting in bouts becoming a total of $12 \mathrm{~min}$ longer over that 7 -d period. Similarly, lying bout duration increased by a total of 26 $\mathrm{min} /$ bout from $\mathrm{d}-7$ to -1 before metritis (4.4 $\mathrm{min} /$ bout $/ d ; 95 \%$ CI $=0.2,8.6 ; P=0.04 ;$ Figure $5 \mathrm{c}$ ) and tended to increase by a total of $11 \mathrm{~min} /$ bout from $\mathrm{d}$ -12 to -1 before DA (back-transformed estimate $=1$ min/bout per day; log-transformed model 95\% CI = $-0.002,0.07 ; P=0.06$; Figure 1e). Correspondingly, cows with metritis (Figure 5d) and DA (Figure 1f) spent an additional $32 \mathrm{~min} / \mathrm{d}(95 \%$ CI $=4.2,59.7)$ and $13 \mathrm{~min} / \mathrm{d}(95 \% \mathrm{CI}=1.8,23.4)$, respectively, lying down each day $(P=0.02$ for both) during those periods. Therefore, the total change in lying time for cows with metritis was $>3 \mathrm{~h} / \mathrm{d}$ over the 6 - $\mathrm{d}$ period, and was $>2 \mathrm{~h} / \mathrm{d}$ for cows with DA over the 11-d period. This suggests that although the number of transitions in and out of resting by cows did not change, cows were spending more time lying down per bout and per day. It was expected that cows would demonstrate increased lying behavior before diagnoses of health disorders because animals often respond to compromised health by increasing resting time (Hart, 1988). However, no predictive changes in lying behavior occurred before SCK and hoof disorders. It is surprising that changes in lying behavior were not detected before treatment of hoof disorders, as previous studies have reported that longer daily lying times (Deming et al., 2013; Westin et al., 2016) and longer lying bouts (Westin et al., 2016) are associated with general lameness in AMS. Kaufman et al. (2016b) found greater lying time for multiparous cows with SCK during wk 3 and 4 of lactation, whereas Itle et al. (2015) noted greater daily standing time for clinically ketotic cows before and on the day of calving. However, Itle et al. (2015) did not detect differences in standing behavior after calving, which is consistent with our SCK results.

A unique aspect of this study was that our analysis controlled for the effect of DIM of cows experiencing health problems. While including DIM as a covariate, associations of days-to-diagnosis of health issues in early lactation were still significant, as were associations with hoof disorders that occurred later in lactation. A DIM effect is particularly important to consider in early lactation, when rumination and milk yield, for example, are increasing until peak lactation; in these cases, rumination or milk yield may not decline with health problems, but may instead fail to increase as expected. Therefore, when choosing settings for AMS alerts to flag cows dropping in milk yield or rumination, default values may not be sensitive enough to identify all problem cows and settings may need to be adjusted to have greater sensitivity or to also include DIM.

The results of this study also suggest the potential for certain measures to be indicative of different types of health disorders, as specific responses were observed in cases of milk temperature, milking frequency, lying 
behavior, and night:day rumination ratios. Given that this was a small study, we can only support the hypothesis that future studies may be able to identify reliable behavior or productivity markers for specific health issues. We acknowledge the small sample size of this study to be a potential limitation and emphasize that this was an exploratory study for which a larger follow-up study is needed. The available sample of cows with data was limited in terms of the variety of disorders analyzed and the number of cases of each disorder, in addition to the compounding effects of some cows experiencing multiple disorders. Particularly for cows experiencing a DA, 3 of the 5 cases occurred in conjunction with preceding issues, which likely contributed to the earlier responses of those variables leading up to diagnosis. However, the majority of other diagnoses took place either independently or at least $7 \mathrm{~d}$ apart from one another. Additionally, diagnoses were made by a combination of barn staff ( 3 individuals) and herd veterinarians (2 individuals). Although this creates potential for diagnostic error and inconsistency, diagnoses were jointly conducted by 2 or 3 individuals each time, thus reducing the effect of individual bias and providing consistent diagnoses for each disorder.

Although this study provided quantitative associations of AMS data with health disorders, it is necessary to explore the efficacy and practicality of using such outcomes for detection models in commercial AMS facilities. Future research should investigate these associations on a larger scale to increase sample size and strengthen the external validity of these results by enrolling several farms, especially those with behavior monitors that can remotely transmit precalving rumination and activity data. Larger sample sizes would also allow for analyses of independent cases of health disorders and would limit cow-level variability in trajectories as seen in the current study. Future studies should utilize specific case definitions to ensure that standardized diagnoses are made between farms. Moreover, objective scoring systems and physiological parameters should be used as much as possible by trained researchers to make diagnoses.

\section{CONCLUSIONS}

This longitudinal pilot study provided evidence that changes in behavior and production may be useful to detect illness and hoof disorders in cows milked with automated systems. Cows had reduced rumination time, BW, activity, and milk yield before being diagnosed with pneumonia and subclinical ketosis. Cows with displaced abomasum also spent less time ruminating, were less active, produced less milk, and spent more time lying down each day with increasing bout duration. During the week before a metritis diagnosis, cows lost weight, were less active, and spent more time lying down each day in longer lying bouts. Cows with hoof disorders had lower rumination time and supplement intake, in addition to reductions in their milking frequency and BW, while they experienced increasing night:day rumination time and milk temperature. Although this was a small study with a limited number of animals having each disorder, behavior and productivity responded differently to various types of health problems and varied at the cow level; therefore, future studies should examine independent cases of health disorders to determine illness-specific measures useful for earlier detection in herds with automated milking systems.

\section{ACKNOWLEDGMENTS}

The authors thank the barn staff at the University of Guelph, Kemptville Campus Dairy Education and Innovation Center (Kemptville, ON, Canada). This project was financially supported by a contribution from the Dairy Research Cluster II Initiative, funded by the Dairy Farmers of Canada (Ottawa, ON, Canada), Agriculture and Agri-Food Canada (Ottawa, ON, Canada), the Canadian Dairy Network (Guelph, ON, Canada), and the Canadian Dairy Commission (Ottawa, ON, Canada).

\section{REFERENCES}

Abramson, J. H. 2011. WINPEPI updated: Computer programs for epidemiologists, and their teaching potential. Epidemiol. Perspect. Innov. 8:1.

Amory, J. R., Z. E. Barker, J. L. Wright, S. A. Mason, R. W. Blowey, and L. E. Green. 2008. Associations between sole ulcer, white line disease and digital dermatitis and the milk of 1824 dairy cows on 30 dairy cow farms in England and Wales. Prev. Vet. Med. 83:381391. https://doi.org/10.1016/j.prevetmed.2007.09.007.

Bach, A., M. Dinarés, M. Devant, and X. Carré. 2007. Associations between lameness and production, feeding and milking attendance of Holstein cows milked with an automatic milking system. J. Dairy Res. 74:40-46. https://doi.org/10.1017/S0022029906002184.

Bicalho, R. C., L. D. Warnick, and C. L. Guard. 2008. Strategies to analyze milk losses caused by diseases with potential incidence throughout the lactation: A lameness example. J. Dairy Sci. 91:2653-2661. https://doi.org/10.3168/jds.2007-0744.

CCAC. 2009. Guidelines on: The care and use of farm animals in research, teaching and testing. Canadian Council on Animal Care, Ottawa, ON, Canada.

Deming, J. A., R. Bergeron, K. E. Leslie, and T. J. DeVries. 2013. Associations of cow-level factors, frequency of feed delivery, and standing and lying behaviour of dairy cows milked in an automatic system. Can. J. Anim. Sci. 93:427-433. https://doi.org/10.4141/ CJAS2013-055.

Dubuc, J., T. F. Duffield, K. E. Leslie, J. S. Walton, and S. J. LeBlanc. 2011. Effects of postpartum uterine diseases on milk production and culling in dairy cows. J. Dairy Sci. 94:1339-1346. https://doi .org/10.3168/jds.2010-3758.

Duffield, T. F., D. F. Kelton, K. E. Leslie, K. D. Lissemore, and J. H. Lumsden. 1997. Use of test day milk fat and milk protein to 
detect subclinical ketosis in dairy cattle in Ontario. Can. Vet. J. 38:713-718.

Elischer, M. F., M. E. Arceo, E. L. Karcher, and J. M. Siegford. 2013. Validating the accuracy of activity and rumination monitor data from dairy cows housed in a pasture-based automatic milking system. J. Dairy Sci. 96:6412-6422. https://doi.org/10.3168/jds.2013 -6790 .

Fogsgaard, K. K., C. M. Røntved, P. Sørensen, and M. S. Herskin. 2012. Sickness behavior in dairy cows during Escherichia coli mastitis. J. Dairy Sci. 95:630-638. https://doi.org/10.3168/jds.2011 -4350 .

Garcia, E., I. Klaas, J. M. Amigo, R. Bro, and C. Enevoldsen. 2014. Lameness detection challenges in automated milking systems addressed with partial least squares discriminant analysis. J. Dairy Sci. 97:7476-7486. https://doi.org/10.3168/jds.2014-7982.

Gáspárdy, A., G. Efrat, A. C. Bajcsy, and S. G. Fekete. 2014. Electronic monitoring of rumination activity as an indicator of health status and production traits in high-yielding dairy cows. Acta Vet. Hung. 62:452-462. https://doi.org/10.1556/AVet.2014.026.

Goldhawk, C., N. Chapinal, D. M. Veira, D. M. Weary, and M. A. G. von Keyserlingk. 2009. Prepartum feeding behavior is an early indicator of subclinical ketosis. J. Dairy Sci. 92:4971-4977. https:// doi.org/10.3168/jds.2009-2242.

Gomez, A., N. B. Cook, M. T. Socha, and D. Döpfer. 2015. Firstlactation performance in cows affected by digital dermatitis during the rearing period. J. Dairy Sci. 98:4487-4498. https://doi.org/10 $.3168 /$ jds.2014-9041.

González, L. A., B. J. Tolkamp, M. P. Coffey, A. Ferret, and I. Kyriazakis. 2008. Changes in feeding behavior as possible indicators for the automatic monitoring of health disorders in dairy cows. J. Dairy Sci. 91:1017-1028.

Green, L. E., V. J. Hedges, Y. H. Schukken, R. W. Blowey, and A. J. Packington. 2002. The impact of clinical lameness on the milk yield of dairy cows. J. Dairy Sci. 85:2250-2256. https://doi.org/10 .3168/jds.S0022-0302(02)74304-X.

Gröhn, Y. T., J. J. McDermott, Y. H. Schukken, J. A. Hertl, and S. W. Eicker. 1999. Analysis of correlated continuous repeated observations: Modelling the effect of ketosis on milk yield in dairy cows. Prev. Vet. Med. 39:137-153. https://doi.org/10.1016/S0167 $-5877(98) 00145-7$.

Hansen, S. S., P. Norgaard, C. Pedersen, R. J. Jorgensen, L. S. Mellau, and J. D. Enemark. 2003. The effect of subclinical hypocalcaemia induced by Na2EDTA on the feed intake and chewing activity of dairy cows. Vet. Res. Commun. 27:193-205. https://doi.org/10 $.1023 / \mathrm{A}: 1023340506782$.

Hart, B. L. 1988. Biological basis of the behaviour of sick animals. Neurosci. Biobehav. Rev. 12:123-137.

Huzzey, J. M., D. M. Veira, D. M. Weary, and M. A. G. von Keyserlingk. 2007. Prepartum behavior and dry matter intake identify dairy cows at risk for metritis. J. Dairy Sci. 90:3220-3233. https:// doi.org/10.3168/jds.2006-807.

Itle, A. J., J. M. Huzzey, D. M. Weary, and M. A. G. von Keyserlingk. 2015. Clinical ketosis and standing behavior in transition cows. J. Dairy Sci. 98:128-134. https://doi.org/10.3168/jds.2014-7932.

Iwersen, M., U. Falkenberg, R. Voigtsberger, D. Forderung, and W. Heuwieser. 2009. Evaluation of an electronic cowside test to detect subclinical ketosis in dairy cows. J. Dairy Sci. 92:2618-2624. https://doi.org/10.3168/jds.2008-1795.

Kaufman, E. I., S. J. LeBlanc, B. W. McBride, T. F. Duffield, and T. J. DeVries. 2016a. Association of rumination time with subclinical ketosis in transition dairy cows. J. Dairy Sci. 99:5604-5618. https://doi.org/10.3168/jds.2015-10509.

Kaufman, E. I., S. J. LeBlanc, B. W. McBride, T. F. Duffield, and T. J. DeVries. 2016b. Short communication: Association of lying behavior and subclinical ketosis in transition dairy cows. J. Dairy Sci. 99:7473-7480. https://doi.org/10.3168/jds.2016-11185.
King, M. T. M., S. J. LeBlanc, and T. J. Devries. 2017. Cow-level associations of lameness, behavior, and milk yield of cows milked in automated systems. J. Dairy Sci. 100:4818-4828. https://doi.org/ 10.3168/jds.2016-12281.

King, M. T. M., E. A. Pajor, S. L. LeBlanc, and T. J. DeVries. 2016. Associations of herd-level housing, management, and lameness prevalence with productivity and cow behavior in herds with automated milking systems. J. Dairy Sci. 99:9069-9079. https://doi .org/10.3168/jds.2016-11329.

Ledgerwood, D. N., C. Winckler, and C. B. Tucker. 2010. Evaluation of data loggers, sampling intervals, and editing techniques for measuring the lying behavior of dairy cattle. J. Dairy Sci. 93:51295139. https://doi.org/10.3168/jds.2009-2945.

Liboreiro, D. N., K. S. Machado, P. R. B. Silva, M. M. Maturana, T. K. Nishimura, A. P. Brandão, M. I. Endres, and R. C. Chebel. 2015. Characterization of peripartum rumination and activity of cows diagnosed with metabolic and uterine diseases. J. Dairy Sci. 98:6812-6827. https://doi.org/10.3168/jds.2014-8947.

Rajala-Schultz, P. J., Y. T. Gröhn, and C. E. McCulloch. 1999. Effects of milk fever, ketosis and lameness on milk yield in dairy cows. J. Dairy Sci. 82:288-294. https://doi.org/10.3168/jds.S0022 -0302(99)75235-5.

Schirmann, K., M. A. G. von Keyserlingk, D. M. Weary, D. M. Veira, and W. Heuwieser. 2009. Technical note: Validation of a system for monitoring rumination in dairy cows. J. Dairy Sci. 92:6052-6055. http://dx.doi.orghttps://doi.org/10.3168/jds.2009-2361.

Schirmann, K., D. M. Weary, W. Heuwieser, N. Chapinal, R. L. A Cerri, and M. A. G. von Keyserlingk. 2016. Short communication: Rumination and feeding behaviors differ between healthy and sick dairy cows during the transition period. J. Dairy Sci. 99:99179924. https://doi.org/10.3168/jds.2015-10548.

Sepúlveda-Varas, P., K. L. Proudfoot, D. M. Weary, and M. A. G. von Keyserlingk. 2016. Changes in behaviour of dairy cows with clinical mastitis. Appl. Anim. Behav. Sci. 175:8-13. https://doi.org/10 .1016/j.applanim.2014.09.022.

Stangaferro, M. L., R. Wijma, C. Quinteros, M. Medrano, M. Masello, and J. Giordano. 2016a. Use of a rumination and activity monitoring for the identification of dairy cows with health disorders: Part II. Mastitis. J. Dairy Sci. 99:7411-7421. https://doi.org/10.3168/ jds.2016-10908.

Stangaferro, M. L., R. Wijma, C. Quinteros, M. Medrano, M. Masello, and J. Giordano. 2016b. Use of a rumination and activity monitoring for the identification of dairy cows with health disorders: Part III. Metritis. J. Dairy Sci. 99:7422-7433. https://doi.org/10.3168/ jds.2016-11352.

Stangaferro, M. L., R. Wijma, C. Quinteros, M. Medrano, M. Masello, and J. Giordano. 2016c. Use of a rumination and activity monitoring for the identification of dairy cows with health disorders: Part I. Metabolic and digestive disorders. J. Dairy Sci. 99:7395-7410. https://doi.org/10.3168/jds.2016-10907.

Urton, G., M. A. G. von Keyserlingk, and D. M. Weary. 2005. Feeding behavior identifies dairy cows at risk for metritis. J. Dairy Sci. 88:2843-2849. https://doi.org/10.3168/jds.S0022-0302(05)72965 -9 .

Van Hertem, T., E. Maltz, A. Antler, C. E. B. Romanini, S. Viazzi, C. Bahr, A. Schlageter-Tello, C. Lokhorst, D. Berckmans, and I. Halachmi. 2013. Lameness detection based on multivariate continuous sensing of milk yield, rumination, and neck activity. J. Dairy Sci. 96:4286-4298. https://doi.org/10.3168/jds.2012-6188.

Westin, R., A. Vaughan, A. M. de Passillé, T. J. DeVries, E. A. Pajor, D. Pellerin, J. M. Siegford, E. Vasseur, and J. Rushen. 2016. Lying times of lactating dairy cows on dairy farms with automatic milking systems and the relation to lameness, leg lesions and body condition score. J. Dairy Sci. 99:551-561. 